November 2019

\title{
From the Editor
}

Welcome to the fall issue of the Journal of Montessori Research. We hope that you enjoy the new layout premiering in this issue. The articles this fall reflect a range of topics including creativity, repetition among preschoolers, and teacher transformation. The first article examines the impact of Montessori education on third-graders' creativity. The second article investigates children's repetitive behavior in a free-play, daycare setting, examining whether repetition is a characteristic behavior of all young children. Finally, the third article explores selected literature on Montessori teacher identity and the effects of teacher identity broadly, including elements of antibias and antiracist teacher-identity development.

As reported in our spring issue, a Montessori Special Interest Group ( $\underline{\mathrm{SIG}})$ now exists within the American

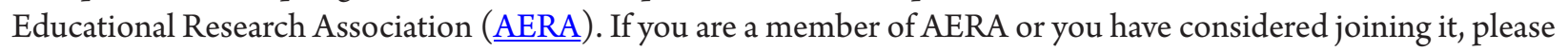
support the new SIG and invite your colleagues to do the same. We are just short of our required 75 members, so we need your help. If you are renewing or joining the organization, you can add the SIG for only $\$ 5$.

Sincerely,

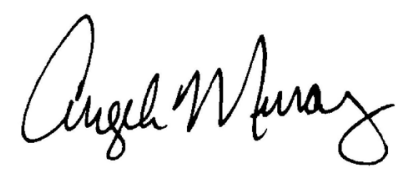

Angela K. Murray, $\mathrm{PhD}$

Editor, Journal of Montessori Research

Director, Center for Montessori Research

Chair, Montessori SIG, AERA

akmurray@ku.edu 